\section{GOVERNANCE FOR ENVIRONMENTAL HUMAN RIGHTS PROTECTION IN THE CONTEXT OF BANGLADESH : A POLICY PERSPECTIVE}

\section{Farid Ahmed*}

\begin{abstract}
The protection of environmental human rights demands an ethical governance frame work. This paper examines the characteristics of three governance models and argues that development planners and policymakers can employ deliberative governance that is nourished by public participation to protect environmental human rights in Bangladesh. The deliberative governance will pave the way to ecological modernization, implement ecologically sustainable development goals, and, in turn, ensure freedom, fairness and good governance since human societies desire to flourish human life.
\end{abstract}

\subsection{Introduction}

The protection of environmental human rights ${ }^{1}$ demands an ethical governance ${ }^{2}$ framework. Governance discourses make

\footnotetext{
* Professor, Department of Philosophy, Jahangirnagar University
} E-mail: farid_ahmed_ss@yahoo.com different available models of governance, which can be classified into three main categories (a) Conventional or Bureaucratic, (b) Market, and (c) Deliberative/discursive. In this paper, I examine the characteristics of those governance models refer to Dryzek (1997, 1998, 2012), Freeman (1997), Gauna (1998), Gleeson and Low (2001), Norton and Hannon (2002), Foster (2002), Young (2000) et al. I argue that development planner and policymakers can employ deliberative governance that is nourished by public participation for the protection of environmental human rights in the context of Bangladesh. The deliberative governance will pave the way to ecological modernization and, in turn, ensure freedom, fairness, and good governance since human societies desire flourishing human life.

\subsection{Conventional Models of Governance}

The main characteristics of conventional governance are topdown control of bureaucrats, vertical distribution of power and centralization of authority. Under this system, the top-level officials develop goals, policies, plans and design strategies. The 'street-level' bureaucrats defend and implement policy. Furthermore, the citizens are either the recipients of benefits or bearers of harm and have a passive role in the decision-making process. They have a low-level capacity to influence and correct the system.

${ }^{1}$ By environmental human rights I mean fair access to environmental goods, livelihood and fair access to decision, information, and justice in resolving environmental matters. Environmental human rights also imply environmental justice (See also Ahmed and Low, 2020).

${ }^{2}$ Ethical governance implies at least the recognition of human freedom and participation rights in decision making. 
The top-down model of governance has some extreme forms. The governance that has been practiced by military rulers, totalitarian societies and some communist nations is regarded as an extreme form of top-down governance. In the extreme form of governance, government interventions are virtually boundless, and citizen participation is notably restricted. Human freedom under such a system stumbles as basic needs, rights and dignity are overlooked. Therefore, this form of governance is neither good nor ethical.

The conventional governing process is profoundly dependent on experts. The experts develop policy by (a) defining the problem, (b) clarifying and ordering the goals, values, and objectives, (c) listing practical means or developing tools to achieve those goals, (d) investigating the critical consequences that would flow from each of the alternatives, (e) comparing these alternative decisions or policies, and (f) choosing the policy with consequences most compatible with the determined ends (Lindblom, 1968, Colebatch, 1998, and Rossi, 1997). Such a formal approach tries to define governance as a scientific activity that requires a comprehensive analysis of possible steps and dimensions by employing our rational faculty to produce a predictable and reliable outcome.

According to Freeman (1997, p. 3), the top-down model proposes a regulative system to force entities to internalize the social and environmental damage caused by development plans. They impose such costs on society based on substantive legal rationality. A conventional governance model achieves this internalization through a strategy of "legalistic enforcement." Environmental agencies issue rules that are binding on a defined class of entities. Agencies create a system of inspection and reporting to monitor compliance with their rules. "Entities that fail to comply are subject to penalties." However, in the modern state system, public participation is considered an essential value for governing policies. The topdown control process lacks such an important ethical aspect of governance. Therefore, for Freeman (1997), conventional governance is undemocratic, inefficient, ineffective, and lacks an ethical foundation.

Conventional governance also lacks either or both accountability and transparency and allows corruption to proliferate. Other deficiencies of this system are that in this process, human freedom is either undervalued or denied. This system also leads to a totalitarian phase where hidden or vested interests shatter humanity and dignity. The top-down model represents the interest of the ruling classes that have worked for centuries to deprive the masses of a fair share of access to the environment and increase the existing disparities and scale of injustices by pushing the masses to a more vulnerable condition.

Besides the conventional criticisms, Norton and Hannon (2002), in their article "Democracy and Sense of Place Value in Environmental Policy", have demonstrated some other limitations of conventional governance. For them, this system of governance cannot develop a fair policy because the topdown model fails to provide justice insofar as it undermines a sense of place value. These authors present the image of a family which is settled in an area for several generations. In their homeland, they have developed their rituals of living, the pattern of economic activities, system of recreation by sharing emotions and knowledge with the local people and the environment. If an offer is made to the family to move to 
another place by estimating resettlement costs and predicting substantial benefits, there is no doubt that such an estimation undermines the place value.

These authors have argued that a system that attempts to quantify value by employing statistical methods is problematic because values are incommensurable. Some of the values (which the family tries to preserve) cannot be captured within a market analysis of social values (Norton and Hannan, 2002, p. 504). The above arguments direct us to conclude that the topdown model is inadequate to produce quality decisions and that the application of market environmentalism (ME), which will be discussed in the later sub-sections, is inappropriate to dispense environmental justice on similar grounds.

Let us consider the offer of compensation to a family to relocate for building a waste dump in their neighborhood. If the family accepts a financial offer for resettlement, that family may receive a new and costly house in a different place. However, the family under discussion loses their "home" and place-relative information such as avoiding risk, collecting food, and when to catch fish. A similar situation arises in the case of the establishment of the 11 Eco-parks of Bangladesh by the Forest Department. This information will not be transmitted without the ongoing connection to the land. Concerning the incommensurability of values, Norton and Hannon (2002, 509) further argue that besides place value, there are many other non-translatable values, information, and experience linked to daily life. These values represent generations of wisdom accumulated from specific experiences and encoded in the cultural information and attitudes passed from generation to generation. Norton and Hannon (2002) conclude by saying that such place-related values are visible in all cultural content, but the form and expression of these experiences may be different in different places. Gadgil and Guha (1992) state that some primitive cultures have developed myths and cultural practices, often religious in nature, that protect the resource base, often termed social capital. Although modern development plans often destroy such myths and practices. The conventional wisdom fails to understand all the non-economic implications of development decisions which have often led to long-term disastrous consequences.

Secondly, centralized control, a top-down system of environmental governance that claims central government sovereignty over state and local governments, conflicts concerning resource use (Norton and Hannon, 2002, 509). Such approaches, on many occasions, indeed undermine the rights of self-determination. Norton and Hannon (2002) have argued that the governance model that recognizes the central government's hierarchical ordering and authoritative power also similarly processes information and value. Critics argue that users of this model aggregate information at the highest level, treating decision-making as a matter of computation of single-scaled values.

Sagoff (1988) rejected the economist centric expertism latent in the top-down model and argued that to make "a hard choice, a public official must organize the minute particulars involved in assessing risk, monitoring compliance, litigating penalties" instead of depending on top-level expertise (Sagoff, 1988, p. 137). The system is also captured by economic rationality, which assumes that some people have a limitless capacity to imagine all possible consequences of a decision, yet the possibility of perceptual error tends to zero. 
According to Gauna (1998), the top-down model is problematic because most technical issues are resolved by applying value judgments, which raises political questions. The problem of applying value judgments in this model is that it presumes objectivity which is an intensely debatable issue. In this model, agency officials may choose the path of least résistance in order to obtain reward and recognition. The command-and-control process is rigid in a sense because changes often take place very slowly. The top-down decisionmaking process is structured in different layers; therefore, responses are sluggish, and information is distorted or lost in the process. Another complaint with such governance is that the public sector is not responsive to the needs of the people. Officials tend to ignore collective interest at the expense of vested private interests.

In many cases, instead of solving the day-to-day problems, they spend time on large projects and seldom assess the consequences of these large projects. Their primary consideration is the immediate financial benefits of the vested interest. These large projects involve vast amounts of resources as well as expertise and energy. These top-level officials also lack the qualifications to deal with complex environmental problems, social contexts, and subtle cultural elements. In the long run, the project fails to achieve its goals. Such failure is a significant loss for the collective because all financial costs and environmental impacts are disproportionately distributed among the mass of people.

One of the most severe complaints that can be made against public sector managers is that they are corrupt, that they spend their time and use public authority and money in developing their fortune so that they can promote the welfare of their family, friends, relatives, and elite of society. For example, in Bangladesh, political and policy decisions primarily reflect powerful vested groups with little reflection of public interest (The Daily Star, 2020). Their actions have raised serious ethical challenges against the top-down governance model. It has been argued that public officials appointed or elected to deliver services to the people are somewhat involved in illegal private business. They allocate permits to serve their vested interest and punish those who challenge and question their unfair and illegal activities (Ahmad, 2004).

Corruption is a severe problem all over the world. Indeed, in many societies, it is an epidemic problem. Research reports by Transparency International, an international NGO that has chapters in different parts of the world, demonstrated that Bangladesh is a 'champion' in corruption (Ahmad, 2004). Many researchers have tried to define and explore the nature of corruption. Ackerman (1999), Larmour et al. (2001), Lindsey and Dick (2002), Clark et al. (1997), amongst others, have investigated the social realities of different societies and explained how the problem of corruption affects human needs, rights and dignity, damages values, escalates social disorganization, renders useless the governance system, obstructs justice, and creates inequalities, mistrust and suffering.

Ackerman (1999) argued that corruption might have roots in culture and history, but it is nevertheless an economic and political problem. It produces inefficiency and unfairness in the distribution of public benefits and costs. It is a symptom that the political system is operating with little concern for the broader public interest. Furthermore, it indicates that the structure of government does not channel private interest 
effectively. Political legitimacy is undermined if a government permits a person to obtain disproportionate private gains at the expense of others' entitlement.

The problems of corruption, the inefficiency of officials, unequal distribution of power, authority and responsibility, lack of accountability, transparency, rejection of human rights and dignity, and problems of values have led researchers to find an alternative to the conventional model. As a consequence, the market model has appeared as another potential candidate in the governance literature. In the following section of the paper, I examine the capacity of this model to resolve environmental justice problems.

\subsection{Market Approaches}

In environmental discourses, market environmentalism is highlighted by economists. They think that social justice is a function of development that is ultimately a variable of economic growth. Therefore, a free market should be in operation to produce efficient and welfare-maximizing levels "of resource use, production, consumption, and environmental protection if the prices of resources, goods, and services capture all of the social costs and benefits of their use (Easty, 1999, p. 1503)." The idea of minimal state intervention, new public management, and corporate governance closely relates to the market model. However, minimal state intervention is supported by market models not to respect the participation value of the citizen; instead, it is viewed as an essential condition for the perfect completion of business and growth.

There are several criticisms of this approach. Critics have labelled the market model as a sophisticated version of the topdown model that rationalizes injustice by coloring decisions and actions to promote public benefit. However, the idea of public good or benefit is a broad category. It has been questioned whether it is fair or ethical if the promotion of the public good disproportionately distributes burdens to a section of the people, restricts their access to basic human needs, undermines dignity, or cuts down the rights for self-determination by reducing autonomy. In this respect, the argument for the market model is not convincing because environmental values are not translatable in prices in the marketplace, as discussed in the previous section. Many authors also criticized market environmentalism (Gleeson \& Low, 1998, Norton \& Hannan, 2002). In favor of market structure, Easty (1999) argued that this model is helpful for the internalization ${ }^{3}$ of all environmental externalities so that societies or businesses can produce efficient outcomes. This process has been putting pressure on ordinary consumers. Tax burdens are shifted and permuted tactfully, and the ultimate bearers are those vulnerable people who live below the safety net.

Like conventional governance, in this system too, the rational actor is responsible for collecting, analyzing, processing data to measure alternative decisions and recommend an optimal level of production, consumption and prices of commodities. The government should act only as a facilitator. This mode of governance accords with the claim that all stakeholders should have the opportunity to pursue their interests. Such a pluralistic model eventually reaches decisions unilaterally.

\footnotetext{
${ }^{3}$ The development process or manufacturing industry displace people, affect human health, damage environment, create waste, etc. There are considered as environmental externalities. To internalize these costs the market model suggests adding such cost as production cost. As a result, burdens are distributed proportionately.
} 
Low and Gleeson (1998) explained the inadequacy of market environmentalism. They have argued that market environmentalism tries to solve the problem through deregulation of all direct state intervention mechanisms and the extension of market relations to all aspects of the environment and society. Limitations of this model include, the state becomes the instrument of the private sector, competes with other states and loses the capacity to promote the public good and its environmental aspects in particular (Low and Gleeson, 1998, p. 161).

The state becomes an instrument of the private sector when environmental regulation and policies are framed to protect businesses of privately owned industries. For example, the state may pass regulations to locate an industry that has the effect of driving out people from their traditional land in order to provide job opportunities and economic benefits. The state policy may drive out environmentally friendly industries to protect industries that monopolize the market.

In this system, one state may deregulate to take advantage of strict regulations of another state by permitting industries that significantly contribute to environmental degradation. There are many recent examples where developing nations are offering similar advantages. For example, Bangladesh has become a lucrative place for investment due to cheap labor and weak environmental regulation. Here foreign investors are protected in many ways. Many rules and regulations are not applied to those privately owned industries. So many polluting industries are located in residential areas, which significantly reduces production costs.

There is about five thousand garments factory in densely populated Dhaka city. The workplace of these industries is not safe and fails to meet standards. As a result, hundreds of workers, mostly female, die due to fire. Most of the tanneries are located in the western part of Dhaka city, where millions of people live. The residents of these areas have suffered poor health for decades. These industries are owned by those who are members of the parliament, so there is a vested interest not to pass any law that will raise production costs. The result is continual suffering for city dwellers (Mahafuzullah, 1999).

Gleeson \& Low (2001, p. 21) argue that the first imperative is to create the possibility of a politics in which many voices can be heard, in which dissent is natural, but in which discussion can result in action on the environmental problems. The governance should create opportunities so that politicians can play such a role with the international actors. The above analysis indicates that both the market and state control models are inadequate to provide such opportunities. It also implies that these models are also inadequate to solve environmental injustice problems that occur in planning.

\subsection{Deliberative Model of Governance}

The development of alternative models has occurred due to the failures of the market and top-down models. Factors such as the typical role of the regulatory regime, the distinctive capacity of alternative dispute resolution (ADR), the influence of different types of environmentalism, evolutionary epistemology, rightsbased philosophies, and the widely acknowledged need for a more creative solution and improved decision-making processes for identifying and distributing the cost and benefit of environmental regulation and natural resource management have all resulted in the development of an alternative model. This alternative approach has been labelled as collaborative 
governance by Freeman (1997), civic republicism by Gauna (1998), deliberative governance by Dryzek (1997, 2012), Fiorino (1999), Hunold (2001), Gleeson and Low (2001). For Easty (1999), it is "optimal" governance, whereas it is empowered participatory democracy for Flynn (2001).

One of the basic characteristics of the model is that the model suggests the integration of meaningful public participation in decision-making processes to ameliorate the longstanding problems of the conventional governance model. The model under discussion also emphasizes sufficient deliberation by the participants, reflected in Plato's The Republic. Considering these common features of the model advanced by the authors, as mentioned earlier, I employ the term 'deliberative governance' to refer to all these versions of the participatory model in the following discussion.

Foster (1998, p. 799) has argued that conventional industry wisdom counsels' private companies to target sites that are in neighborhoods "least likely to express opposition" that is poorly educated and lower socioeconomic neighborhoods with little if any commercial activity. In contrast, the new approach develops policies and plans through the meaningful participation of micro-level communities to characterize the features of deliberative governance. The conventional mode of governance develops policies by employing cooperative risk assessment techniques, measuring a utilitarian matrix, and appealing to compensation apparatuses. However, this deliberative governance tries to respect the experience of affected communities, values and choices of ordinary citizens and considers the inadequate access of the suffering class in the decision-making systems.
Several reasons influenced the emergence of such a revolutionary perspective. Kooiman (1993) argues that certain conditions support the transformation to social-political governance that takes the form of deliberative governance. These are that (a) existing traditional structures of authority, methods and instruments, have failed or eroded; (b) new fields of social-political activities exist in which organizational forms and patterns of interest-mediation are not (yet) strongly established; (c) some issues are of great concern to the (public and private) actors that are involved, and (d) there must be sufficient convergence of objectives and interests to make it possible to reach a synergetic effect or a 'win-win' situation. Other conditions relate to the state of mind' of the actors involved. These include a certain amount of minimal trust or mutual understanding, a certain preparedness to take collective responsibility, and a certain degree of political involvement and social support.

The deliberative model is crucial as it creates the first window, the only window to express the stakeholders' opinions to enhance the legitimacy of decisions by checking the full discretion of the administrator. The creation of windows for public participation can be considered an initiative to integrate the interests of all involved (Freeman, 1997). Such access to policymaking and planning paves the way to exercise various types of human freedom and fundamental human rights. To reduce the market failure, fill regulatory gaps, and create the opportunity for innovative solutions, Freeman (1997) also proposes increasing the number of such windows. Freeman (1997) argues that society needs a form of governance for environmental justice that should be conducive to producing effective, implementable, and legitimate rules, that must 
reward problem-solving instead of adversarial systems, where parties should not miss opportunities to engage constructively, and the system should give 'ownership' to the people over the rule-making process. Furthermore,

the goal of efficacy and legitimacy are better served by the deliberative model [Freeman has termed collaborative] that views the governance as a problemsolving exercise in which parties share responsibility for all stages of the rule-making process in which solutions are provisional, and the state plays an active if varied role(Freeman,1997, p. 6).

For Freeman (1997), deliberative governance as a structure has the potential to create a condition where a self-steering network evolves for innovative decisions. In this kind of political environment, all social forces play an active role in shaping community life in the direction that can fulfil their environmental needs.

This form of governance is practiced in many policy domains in the USA. Freeman (1997) has examined some cases to demonstrate the potential capacity of such governance that encouraged decision-makers to be united through deliberation. Freeman has found some successes as well as many pitfalls, dangerous curves which diminish its effectiveness. Nevertheless, Freeman argued in favor of developing deliberation and public participation practices in governing policies, so that stakeholders enjoy the opportunities to negotiate the context of a comprehensive policy and comply with varieties of environmental laws.

Beierle (1999) noted some of the crucial promises of this participatory model. The framework aimed to alleviate the inflexibility and inequity, facilitate a deliberative partnership between public and private citizens and between traditional adversaries among private stakeholders, educate the public, increase the substantive quality of decisions, and incorporate public values in decision-making and rebuilding trust in government agencies. Likewise, Foster (2002) has argued that the participatory model promises a more deliberative process which is absent in the market-based model 'interest representation'. In this process

[p]ublic and private stakeholders are expected to come together to find common solutions for mutual problems, allowing them not only to deliberative activity in achieving "long-term ecosystem health" in their communities but also to foster linkage between socioeconomic prosperity and environmental wellbeing (Foster, 2002, p. 480).

Foster (2002) also raised questions that diminish the model's applicability by examining some practices of the USA government agencies, including the EPA, which tries to follow negotiated rule-making process blurring the demarcation line drawn in the past between private and public perspectives. Foster (2002) asks can this partnership produce equitable decisions moulding diversified interests of the contested participants, to what extent devolution ensures deep civic participation in environmental decision making, and whether devolved collaboration succeeded in expanding the ranges of values and expertise available to the process.

The participatory models have been criticized for the same reasons as traditional governance. One of the crucial problems of traditional governance is the concentration of power where 
the executive branch holds unlimited discretionary power and significantly dominates both the legal and legislative process. The growing concern about the nature of such exercise of power leads researchers to explore ideas of more flexible governance to ensure accountability, transparency and above all, the dignity of the citizens of the country. Critics have argued that the projected new pattern of governance also fails to ensure the proper distribution of power. The central theme of the participatory process is the empowerment of the citizen for whom all state-led decisions are made. Ironically, it is true that the regulatory regime works as an 'invisible hand' in this new process and exploits the ignorance and innocence of the mass of people.

\subsection{Deliberative Process in the Context of Bangladesh}

As environmentalism gathers momentum, many Western scholars recommend a deliberative model to revolutionize the decision-making process under the rubric of Sustainable Development. This leads to the question, whether such a Western model can play a significant role in Bangladesh - a society that lacks a congenial political environment, acceptable decision-making framework, formal judicial independence, and expertise to deal with subtle and complex environmental problems. I want to argue that similar conditions exist in Bangladesh, identified by Kooiman (1993). The people of Bangladesh and development partners of the country identify the same need that the nation should reform the conventional patterns of decision-making and other state lead systems to show respect to the demands of society. Besides, I argue that for the following reasons, the deliberative approach, which tries to integrate the participation of the community and deliberation of the participants, seems the best form of governance for achieving objectives like environmental justice in the context of Bangladesh.

In the first place, deliberation is a valuable tool to clarify environmental problems to the project's stakeholders. Second, the participation of citizens contributes to reducing complexity and overcoming ethical dilemmas (Foster, 2002). Third, deliberative governance as a system was in existence in the past in many societies of developing nations while bureaucratic systems were non-existent.

The most crucial logic is that the idea of public participation is embedded in Bangladesh culture and still produces effective outcomes to resolve micro-level disputes in the rural areas of Bangladesh (UNDP, 2002). This system, known in Bangladesh as Alap-alochona or songlap, means critical discussion and reflection to understand and solve the problem.

Involvement of the community in the decision-making process passes a message to the citizens that they are important to the authority. Respecting their views and valuing experience and culture, the system also gives a sense of ownership to the community. The problem of accountability is solved by shared responsibility, and decisions attain legitimacy and transparency. The system also contributes to improving the knowledge of the participants by creating scope for learning.

For instance, the community describes the day-to-day experiences they encounter. On the other hand, representatives of the authority learn the nature of the problem from the community. The experts also explain intricate causal relationships and the possible outcome of any decision. In this 
way, the choices of stakeholders are enlarged, and many voices are heard. Besides, the dignity of all stakeholders is respected.

Fung and Wright (2003) also indicate that the reinvention of such a participatory system may function properly in Bangladesh because of its success in Kerala and West Bengal of India. These two states are immediate neighbors of Bangladesh and have similarities in different aspects, such as the social, political, and economic culture. Adopting such a model should open new prospects at all levels of decisionmaking at this critical juncture when people of Bangladesh are dissatisfied when they witness the conventional role of the bureaucracy, and political leaders are ready to integrate environmental matters in the decision-making process of ecological modernization. This claim is corroborated by case study results (Ahmed, 2005, 2010).

Although it is not part of this study, nevertheless, I should mention here that in addition to a deliberative process of decision-making, political stability, commitment for change, and an enhanced level of education, political will and judicial independence are also important aspects of environmental justice governance in the context of Bangladesh (World Bank, 2002). These should strengthen the decision-making process and create the opportunity to ethically resolve environmental disputes in the courts and other decision-making places.

The problem of criterion may jeopardize prospects of critical deliberation at a grassroots level. For example, affected community members may be captured by similar sorts of predicaments and argue in favor of strong verification of some environmental problems. In this regard, participants may argue that falsifiability should be the criterion of elimination. There are chances that such philosophical debates may arise at all levels of the decision-making process. We need to develop a framework that will adopt a suitable ethical methodology to refine ideas and perspectives. This task cannot be solved at a grassroots level.

A tendency among decision-makers is to view environmental justice issues concerning environmental pollution control. They understand the concept of the environment from a narrow perspective. It is a matter that the environment covers all spheres of life, and environmental problems are essentially interrelated with all economic development and social, cultural, and political activities (Falk, 2001, p. 221). Therefore, a framework for environmental justice governance should be adopted from a broader perspective - the deliberative approach in this respect a promising candidate in the context of Bangladesh.

\subsection{Conclusion}

In the preceding sections, I examined existing theories of governance to indicate a framework that can be used in Bangladesh. The study of governance indicates that bureaucratic and market models are inadequate to create fair access to environmental resources and decision-making processes. Both these models challenge human dignity and undermine some critical values such as the sense of place, importance of public participation, and knowledge of the community acquired through experience for addressing environmental problems. These systems also employ defective conceptual tools such as utilitarian matrix, suitable risk assessment methods and attempts to quantify incommensurable human values. On the other hand, the deliberative model 
promises to ensure meaningful participation of all stakeholders, acknowledges the values and expertise of the community, and opens avenues to empower both the state and citizens to address the problems of accountability, transparency, and legitimacy.

History reveals that the people of Bangladesh value human rights and dignity above their needs. They have struggled for participation rights as part of establishing their dignity. For example, during the colonial period, the East India Company applied force to ensure indigo production. The farmers of Bengal opposed the decision and struggled for many years for self-governance (Wolpert, 2000). Also, after independence from colonial rule, the people of Bangladesh fought for selfruled governance for 23 years. These two great justice movements were ultimately based not only on needs nor on rights but dignity.

The literature indicates that the idea of deliberation is primitive and embedded in the political culture of Bangladesh. For instance, such systems were practiced for several centuries before to rising of the state system ${ }^{4}$. I would like to argue that the deliberative model may be suitable in Bangladesh, although it is developed primarily to address the problems of developed nations that have adequate resources and sufficient expertise.

${ }^{4}$ Before 1793 there were local informal governing systems in operation in Bangladesh. In the year 1793 the then British government took control the administration and proclaimed those informal systems as invalid. Subsequent governments never changed the law although the colonial system does not exist. In addition, such system is still practiced at grass root levels. However, those systems are not regarded as valid (UNDP: 2002, Wolpart: 2000).

\section{Bibliography}

Ackerman, S. R. (1999). Corruption and Government, Causes, Consequences, and Reform, Cambridge University Press, USA.

Ahmed, F. (2005). Environmental Justice and Governance, The Problems of the Madhupur Garo Community in Bangladesh, A thesis, UNSW.

Ahmed, F. (2010). Fair Access to Environmental Justice in Poor Nations: Case Studies in Bangladesh, A Thesis, The University of Melbourne.

Ahmed, F., and Low, N. (2020). Environmental justice dialogues and the struggle for human dignity in the deciduous forest of Bangladesh, Journal of Political Ecology, Vol. 27, No. 1, pp. 300-316.

Ahmad, M. et al. (2004). National Integrity Systems Transparency International Country Study Report Bangladesh 2003, Transparency International, Dhaka.

Bowornwathana, B. (July 2000). Governance reform in Thailand, Questionable assumption, Uncertain Outcomes, Governance, $A n$ International Journal of Policy and Administration, Vol. 13, No. 3.

Blowers, A \& Evans, B. (1997).Town Planning into the $21^{\text {st }}$ Century, Routledge, London.

Breger, M.J. (1996). Government accountability in the twenty-first century, University of Pittsburgh Law Review, Vol.57, pp. 423-.

Brown, J.G. (2000), Ethics in environmental ADR, an overview of issues and some overarching questions, Valparaiso University Law Review, Vol. 34.

Clark, G. L., Elizabeth Prior Johnson \& Wayne Caldow (edited). (1997). Accountability and Corruption Public Sector Ethics, Allen \& Unwin, Australia. 
Coglianese, C. (1997). Assessing consensus, The promise and performance of negotiated rule-making, Duke Law Journal, Vol. 46, p. 1255.

Colebatch, H. (1998). Policy, U.K, Open University Press.

Desai, U (edited). (1998). Ecological Policy and Politics in Developing Countries, Economic Growth, Democracy, and Environment, New York, State University of New York Press.

Dicson, A. K. (1997). Development and International Relations, A Critical Introduction, U. K, Polity Press.

Dryzek, J. S. (1997). The Politics of the Earth, Environmental Discourses, U.K, Oxford University Press.

Dryzek, J.S \& Schlosberg, D. (1998). Debating Earth, the Environmental Politics Reader, New York, Oxford University Press.

Dryzek, J.S \& Niemeyer, S. (2012). Foundations and Frontiers of Deliberative Governance, U.K., Oxford University Press.

Esty, D.C. (1999). Toward optimal environmental governance, New York University Law Review, Vol. 74, No. 6, pp. 1495-1574.

Falk, R. (2001). Human Governance and the Environment, Overcoming Neo-Liberalism, In Gleeson, B \& Low, N (edited). (2001). Governing for the environment, global problems, Ethics and Democracy, Great Britain, Palgrave.

Fiorino, D. J. (1999). Rethinking environmental regulation, perspectives on law and governance, Harvard Environmental Law Review, Vol. 23, pp. 1-26.

Flynn, P. D. (2000). Finding Environmental Justice Amidst Brownfields Redevelopments, Virginia Environmental Law Journal, Vol. 19, pp. 463-490.

Foster, S. (1998). Justice from the ground up, distributive inequities, grassroots resistance, and the transformative politics of the environmental justice movement, California Law Review, Vol. 86, pp. 775-841.
Foster, S. (2002). Environmental justice an era of devolved collaboration, Harvard Environmental Law Review, Vol. 26, pp. 459-498.

Freeman, J. (1997). Collaborative Governance in the Administrative State, University of California Los Angeles Law Review, Vol. 45, Issue 1, pp. 1-98.

Fung, A \& Wright, E.O. (2003). (ed.), Deepening Democracy, Institutional Innovations in Empowered Participatory Governance, London, Verso.

Gadgil, M. \& Guha, R. (1992). The fissured land: An ecological history of India, Delhi, Oxford University Press.

Grugel, J. (2002). Democratization, a Critical Introduction, China, Palgrave.

Gleeson, B \& Low, N (edited). (2001). Governing for the Environment, Global Problems, Ethics and Democracy, Great Britain, Palgrave.

Gauna, E. (1998). The environmental justice misfit, public participation and paradigm paradox, StanfordEnvironmental Law Journal, Vol. 17, pp. 3-72.

Hunold, C. (2001). Corporatism, pluralism, and democracy, towards a deliberative theory of bureaucratic accountability, Governance, An International Journal of Policy and Administration, Vol. 14, No. 2.

Hult, K.M. and Walcot, C. (1990), Governing public Organizations, CA, Pacific Grove.

Knight, B., Hope, C. \& Tandon, R. (2002). Reviving Democracy Citizen at the Heart of Governance, London, Earthscan.

Kibert, N. (2001). Greening justice, a holistic approach to environmental injustice, Journal of Land Use and Environmental Law, Vol. 17, No.1, pp. 169-182. 
Kooiman, J. (1993). Modern Governance, New Government Society Interactions, London, SAGE Publication.

Kuehn, R.R. (1996). The limits of devolving enforcement of federal environmental laws, Tulane Law Review, Vol. 70, No. 6, pp. 2373-2396.

Lafferty, M \& Meadowcroft, J (eds.). (1996). Democracy and the Environment, Problems and Prospects, Edward Elgar, Cheltenham, UK.

Larmour, P \& Nick Wolanin (edited). (2001). Corruption and Anticorruption, Asia Pacific Press, Australia.

Little, W \& Eduardo Posada-Carbo. (edited) (1996). Political Corruption in Europe and Latin America, Macmillan Press Ltd., U.K.

Lindblom, C.E. (1959). The Science of Muddling Through, Public Administration Review, Vol. 19, pp. 78-88.

Lindblom, C.E. (1979). Still muddling, not yet through, Public Administration Review, Vol. 39, pp. 517-26.

Lindsey, T \& Dick, H. (2002), Corruption in Asia, Rethinking the Government Paradigm, Australia, The Federation Press.

Lundqvist, L. (2001). Implementation from above, the ecology of power in Sweden's environmental governance, Governance, An International Journal of Policy and Administration, Vol. 14 No. 3, pp. 319-337.

Macey, G.P and Susskind, L.E. (2001). The secondary effects of environmental justice litigation, The case of West Dallas Coalition for environmental justice V. EPA, Virginia Environmental Law Journal, Vol. 20, pp. 431-477.

Mashaw, J.L. (1996). The panel, the structure of government accountability, University of Pittsburgh Law Review, Vol. 57, pp. $405-422$.
Myer, J.M. (2001). Political Nature, Environmentalism and the Interpretation of Western Thought, Cambridge: The MIT Press.

Miller, C.A \& Edwards, P. N. (2001). Changing the atmosphere, expert knowledge and environmental governance, Cambridge: The MIT Press.

Norton, B.G \& Hannon, B. (2002). Democracy of place values in environmental policy, In Light, Andrew and Rolston III, Holmes. (edited). 2003. Environmental Ethics: An Anthology/ USA, Wiley \& Blackwell.

OECD. (1999). Governance and Public Management, Vol-vii, Paris

OECD. (2002). Public sector transparency and accountability make it happen, France OECD.

O, Neill, C.A. (2000). Variable justice, environmental standards, contaminated fish, and "acceptable" risk to native peoples, Stanford environmental law journal, Vol. 19, pp. 3-118.4.

Pellow, D.N \& Brulle, R.J (eds.). (2005). Power, Justice and the Environment- A Critical Appraisal of Environmental Justice Movements, Cambridge: The MIT Press.

Peters, B.G \& Pierre, J. (2000). Citizens versus the New Public Manager, The problem of Mutual Empowerment, Administration and Society, Vol. 32, No. 1, pp. 9-28.

Peterson, M.A. (2000). The fate of "Big Government" in the United States, Not Over, But Undermined? Governance, An International Journal of Policy and Administration, Vol. 13, No. 2.

Pierre, J (edited). (1995). Bureaucracy in the Modern State, an Introduction to Comparative Public Administration, USA: Edward Elgar.

Popper, K. R. (1972). The Logic of Scientific Discovery, London: Hutchinson. 
Rhodes, R.A.W. (1997). Understanding Governance, Policy Networks, Governance, Reflexivity and Accountability, Buckingham, Open University Press.

Rosenau, J.N and Czempiel, E.O. (1998). Governance without Government, order and change in world politics, U.K: Cambridge University Press.

Rossi, J. (1997). Participationrun amok, the costs of mass participation for deliberative agency decision-making, Northwestern University Law Review, Vol 92, pp. 173-249.

Sagoff, M. (1988). The Economy of the Earth, New York: Cambridge University Press.

Sbragia, A.M. (2000). Governance, the State, and the Market, What is Going On? Governance, An International Journal of Policy and Administration, Vol. 13, No. 2, pp. 243-250.

Stenmark, M. (2002). Environmental Ethics and Policymaking, England: Ashgate.

Shane, P.M (1996). Back to the future of the American state, overruling Buckley v. Caleo and other Madisonian steps, University of Pittsburgh Law Review, Vol. 57, pp. 443-459.

Santiago, T.M. (2001). An ounce of preemption is worth a pound of cure, state preemption of local siting authority as means for achieving environmental equity, Vermont's Journal of the environment, Vol. 2, No. 1, pp. 71-113.

The Daily Star Staff Correspondent. (2020). TI Corruption Index 2019: Bangladesh moves three notches up, https://www. thedailystar.net/backpage/news/ti-corruption-index-2019bangladesh-moves-three-notches-1858261, Accessed on /01/01/ 2021.

Transparency International (2003). http,//www.ti-bangladesh.org/ TIB-doc/newsscan-database/1096009204-main-bangla-report. doc. Accessed /20/04/2004.

United Nations Development Program (UNDP). (2002). Human Security in Bangladesh- In search of Justice and Dignity, UNDP, Bangladesh.
Warren, M.E. (edited). (1999). Democracy \& trust, U.K: Cambridge University Press.

Weller, P., Herman, B., and Rhodes, R.A.W. (1997). The Hollow Crown, Countervailing Trends in Core Executives, U.K: Macmillan Press Ltd.

Wilson, G.K. (2000). Introduction, Governance, An International Journal of Policy and Administration, Vol. 13, No. 2, pp. 233 234.

Wilson, G.K. (2000). In a state? Governance, An International Journal of Policy and Administration, Vol. 13, No. 2, pp. 235242.

World Bank (March 2002), Taming Leviathan, Reforming Governance in Bangladesh, Dhaka, World Bank.

Wolpert, S. (2000). A New History of India, Sixth Edition, New York, Oxford University Press.

Yang, T. (2002). Melding civil rights and environmentalism, finding environmental justice's place in environmental regulation, Harvard Environmental Law Review, Vol. 26, pp. 10-32.

Young, I.M. (2000). Inclusion and Democracy, New York, Oxford University Press. 